\title{
Rates and causes of mortality in Endangered African wild dogs Lycaon pictus: lessons for management and monitoring
}

\author{
Rosie Woodroffe, Harriet Davies-Mostert, Joshua Ginsberg, Jan Graf, Kellie Leigh, Kim McCreery, Gus Mills, \\ Alistair Pole, Gregory Rasmussen, Robert Robbins, Michael Somers and Micaela Szykman
}

\begin{abstract}
Effective species conservation depends upon correctly identifying the threats that cause decline or hinder recovery. Because estimates of the relative viability of different populations of Endangered African wild dogs Lycaon pictus are most strongly influenced by adult and pup mortality, we analysed rates and causes of mortality in eight wild dog populations under study in southern and eastern Africa. The probabilities of detecting wild dog deaths were influenced by the monitoring methods used. The least biased estimates of mortality causes were obtained through intensive monitoring of radio-collared individuals; this is impossible for pups, however. Mortality patterns varied substantially between populations. Rates
\end{abstract}

of human-caused mortality were higher for wild dogs radio-collared outside protected areas than for those collared inside, but rates of natural mortality were comparable, suggesting that anthropogenic mortality is additive to natural mortality. The relative importance of factors such as snaring and infectious disease also varied regionally. Hence, although our analyses identified no new threats beyond those highlighted in a 1997 rangewide Action Plan, they suggest that local plans will be valuable to target conservation activities more precisely.

Keywords African wild dog, carnivore, humanwildlife conflict, intraguild predation, Lycaon pictus, radio telemetry, snare, wildlife disease.
Rosie Woodroffe (Corresponding author) Department of Wildlife, Fish \& Conservation Biology, University of California, 1 Shields Ave, Davis CA 95616, USA. E-mail rwoodroffe@ucdavis.edu

Harriet Davies-Mostert Venetia Limpopo and Marakele Wild Dog Projects, Endangered Wildlife Trust, PO Box 476, Musina 0900, South Africa.

Joshua Ginsberg Wildlife Conservation Society, 2300 Southern Boulevard, Bronx, NY 10460-1099, USA.

Jan Graf School of Biological and Conservation Sciences, University of KwaZulu-Natal, Durban 4041, South Africa.

Kellie Leigh African Wild Dog Conservation, PO Box 80, Mfuwe, Eastern Province, Zambia.

Kim McCreery and Robert Robbins African Wild Dog Conservancy, PO Box 30692, Tucson, AZ 85751, USA.

Gus Mills SANParks/Endangered Wildlife Trust, Private Bag X402, Skukuza 1350, South Africa.

Alistair Pole 19 Rolf Avenue, Ballantyne Park, Harare, Zimbabwe.

Gregory Rasmussen Wildlife Conservation Research Unit, Tubney House, Abingdon Road, Tubney, Oxon, OX13 5QL, UK.

Michael Somers Centre for Wildlife Management, Centre for Invasion Biology, University of Pretoria, Pretoria 0002, South Africa.

Micaela Szykman* Smithsonian National Zoological Park Conservation and Research Center, 1500 Remount Road, Front Royal, VA 22630, USA.

${ }^{*}$ Current address: Department of Wildlife, Humboldt State University, 1 Harpst Street, Arcata, CA 95521, USA.

Received 10 October 2005. Revision requested 16 January 2006. Accepted 26 April 2006.

\section{Introduction}

Effective conservation of any species depends upon correctly identifying the threats that cause decline or hinder recovery. Only by identifying these threats can the most appropriate conservation activities be determined (Caughley, 1994). The African wild dog Lycaon pictus is one of the world's most threatened carnivores. Formerly widespread in Africa south of the Sahara, wild dogs have disappeared from 25 of the 39 countries they formerly occupied despite the persistence, in many areas, of apparently suitable habitat, prey, and other large carnivore species. The total population is estimated at $<6,000$ wild dogs and the species is categorized as Endangered on the IUCN Red List (IUCN, 2006) on the basis of small population size and ongoing decline (Woodroffe et al., 2004).

Analyses of threats to wild dog populations (Woodroffe et al., 1997; Creel \& Creel, 1998; Woodroffe et al., 2004) have highlighted two key features of the species' ecology that contribute to its vulnerability. Firstly, population densities are low even in pristine habitat; hence only large areas can support viable populations. Secondly, home ranges are large; hence packs living in all but the largest protected areas are exposed to potential threats beyond reserve borders. Both low population densities and wide ranging behaviour of wild dogs appear to reflect interaction with larger predators, particularly lions Panthera leo and 
hyaenas Crocuta crocuta. Predation is an important cause of wild dog mortality and, in some ecosystems at least, wild dog kills may be stolen by larger competitors (Creel \& Creel, 1996). Probably as a consequence, wild dogs tend to avoid areas of high prey density favoured by larger carnivores, and consequently have large home ranges (Creel \& Creel, 1996; Mills \& Gorman, 1997). Whether these interactions with competing predators represent a threat to wild dogs or are predisposing factors that make wild dogs more vulnerable to habitat fragmentation is a matter for debate (Creel \& Creel, 2002; Woodroffe, 2003).

Discussions of threats to wild dogs have focused on causes of adult mortality (Woodroffe et al., 1997; Creel \& Creel, 2002) because population viability analyses suggested that it is a key demographic variable determining the persistence of model wild dog populations (Woodroffe et al., 1997; Mills et al., 1998). More recent analyses suggest that pup mortality may be as important as, or even more important than, adult mortality (Cross \& Beissinger, 2001; Creel et al., 2004). Hence, consideration of the factors contributing to wild dog mortality remains a valuable starting point to evaluate proximate threats to the persistence of populations. Such analyses must, however, take account of two caveats. Firstly, not all mortality causes are threats; all animals have to die of some cause, and factors that cause mortality, even if they are anthropogenic, may have no effect on population viability if they simply kill animals that would otherwise have died of other causes. Secondly, because causes of mortality vary from place to place, conclusions will be influenced by the locations where wild dogs are under study. Of necessity, most studies have been performed in areas (often protected areas) where wild dog populations are persisting relatively well, and this limits the possibilities for extrapolation to regions where populations may face greater extinction risks but where no studies have been performed. Despite these caveats, consideration of rates and causes of mortality in current study populations is at least a first step in identifying factors that could threaten wild dog populations.

Threats to the persistence of African wild dogs were last formally assessed during preparation of an IUCN Action Plan (Woodroffe et al., 1997). However, it was recognized at that time that threatening processes are dynamic. The Action Plan therefore recommended that monitoring continue at established long-term sites to identify new threats and to determine whether old threats were still relevant. At an international workshop (Woodroffe et al., 2005a) we re-evaluated threats to wild dogs using updated data from a larger sample of areas, and also assessed whether ongoing monitoring programmes were effectively measuring potential threats.

\section{Methods}

We collated mortality data from eight study areas where individual wild dogs were systematically monitored using radio-telemetry (Table 1). Most studies also used photo-ID (Maddock \& Mills, 1994) to monitor uncollared individuals, as well as reporting deaths of nonstudy animals not individually identified. Confirmed or suspected causes of death were recorded where known; other deaths were recorded as 'unknown cause'. In a few instances, multiple factors apparently contributed to death; e.g. one wild dog was killed by hyaenas many months after losing a leg to a snare. In such cases mortality was attributed to the proximate cause of death (hyaenas in the example given); the number of such instances was small enough not to influence overall conclusions. Mortalities were classified as humancaused (e.g. road accident, snared, shot) or natural (e.g. predation, intraspecific aggression, hunting injury). Deaths due to infectious disease were classified separately because some infections (e.g. anthrax) are probably natural whereas others (e.g. rabies, distemper) can be contracted from domestic dogs and might thus be ultimately caused by humans.

We also recorded the location of each death as inside or outside protected areas. Protection status was actively enforced (e.g. through anti-poaching patrols) in all the protected areas listed in Table 1, although the intensity of enforcement varied. Unprotected areas listed in Table 1 comprised private and communal land used primarily for raising livestock; game ranching and cultivation were also practiced in the environs of some protected areas.

We estimated mortality rates using radio-telemetry data. We recorded the date each wild dog was first radio-collared, whether it was collared inside or outside a reserve, and either the date that monitoring ceased (e.g. because of collar failure, dispersal from the study area, or completion of the study) or the date that the individual was confirmed dead. These data were converted into mortality rates using an extension of the Kaplan-Meier procedure to permit staggered entry of individuals (Pollock et al., 1989). Where mortality agents vary substantially between monitoring periods (e.g. seasons) cause-specific mortality rates allow the most accurate assessment of mortality causes (Heisey \& Fuller, 1985). However, in the absence of consistent seasonality across sites there was no a priori reason to expect temporal variation in mortality causes, and we therefore used simple proportions of deaths due to different causes to approximate cause-specific mortality.

Although we wished to compare mortality rates of wild dogs living inside and outside protected areas, variable (and sometimes intermittent) monitoring made 
Table 1 Summary of data from eight monitoring studies of African wild dogs (in areas both protected and unprotected), with sample sizes of radio-collared animals, animals that were individually recognized but not radio-collared, and animals that were found dead but were not members of study packs. No attempt was made to collate data on numbers of pups studied because sites varied substantially in the intensity of monitoring and hence in their ability to estimate pup mortality. Animals were only considered confirmed dead if a carcass or radio collar was retrieved; lost animals are those whose fates were unknown due to disappearance, dispersal or collar failure.

\begin{tabular}{|c|c|c|c|c|c|c|c|c|c|c|}
\hline \multirow[b]{2}{*}{ Study area } & \multirow[b]{2}{*}{ Protected? } & \multirow{2}{*}{$\begin{array}{l}\text { Years } \\
\text { of study }\end{array}$} & \multicolumn{3}{|c|}{ Radio-collared $^{1}$} & \multicolumn{3}{|c|}{ Identified not collared $^{1}$} & \multirow{2}{*}{$\begin{array}{l}\text { Not } \\
\text { identified }^{1} \\
\text { Dead }\end{array}$} & \multirow{2}{*}{$\begin{array}{l}\text { Pups } \\
\text { Dead }\end{array}$} \\
\hline & & & Number & Dead & Lost & Number & Dead & Lost & & \\
\hline $\begin{array}{l}\text { Kruger National } \\
\text { Park, South Africa }\end{array}$ & Yes & $\begin{array}{l}1989- \\
2004\end{array}$ & 89 & 41 & 43 & 292 & 34 & 258 & 7 & 68 \\
\hline $\begin{array}{l}\text { Hluhluwe-iMfolozi } \\
\text { Park, South Africa }\end{array}$ & Yes & $\begin{array}{l}1997- \\
2004\end{array}$ & 13 & 6 & 1 & 34 & 2 & 18 & 0 & 4 \\
\hline $\begin{array}{l}\text { Venetia Limpopo } \\
\text { Reserve, South Africa }\end{array}$ & $\begin{array}{l}\text { Yes } \\
\text { (private) }\end{array}$ & $\begin{array}{l}2002- \\
2004\end{array}$ & 9 & 1 & 3 & 21 & 2 & 3 & 0 & 0 \\
\hline $\begin{array}{l}\text { Marakele National } \\
\text { Park, South Africa }\end{array}$ & Yes & $\begin{array}{l}2002- \\
2004\end{array}$ & 4 & 0 & 0 & 26 & 6 & 4 & 0 & 0 \\
\hline $\begin{array}{l}\text { Lower Zambezi } \\
\text { National Park, Zambia }\end{array}$ & Yes & $\begin{array}{l}2000- \\
2004\end{array}$ & 4 & 3 & 0 & 21 & 4 & 16 & 0 & 1 \\
\hline $\begin{array}{l}\text { Hwange National Park } \\
\text { \& nearby lands, } \\
\text { Zimbabwe }\end{array}$ & Partly & $\begin{array}{l}1990- \\
2004\end{array}$ & 79 & 46 & 26 & & 13 & & 0 & $22^{2}$ \\
\hline $\begin{array}{l}\text { Savé Valley } \\
\text { Conservancy, } \\
\text { Zimbabwe }\end{array}$ & $\begin{array}{l}\text { Yes } \\
\text { (private) }\end{array}$ & $\begin{array}{l}1996- \\
2004\end{array}$ & 3 & 3 & 0 & & 24 & & 33 & 17 \\
\hline $\begin{array}{l}\text { Samburu \& Laikipia } \\
\text { Districts, Kenya }\end{array}$ & No & $\begin{array}{l}2001- \\
2004\end{array}$ & 26 & 9 & 5 & & 0 & & 13 & 1 \\
\hline Total & & & 227 & 109 & 78 & $394^{3}$ & $48^{3}$ & $299^{3}$ & 53 & 112 \\
\hline
\end{tabular}

${ }^{1}$ Adults and yearlings only

${ }^{2}$ Data from Woodroffe et al. (2004)

${ }^{3}$ Excludes Hwange, Savé \& Samburu-Laikipia, because the number of study animals was not known/not reported from these three sites.

it impossible to estimate, consistently across studies, the time each individual spent inside and outside reserves. We therefore compared mortality rates between wild dogs radio-collared inside vs outside protected areas, using a log-rank test (which gives a test statistic distributed as $\chi^{2}$; Pollock et al., 1989). This analysis was based upon collaring locations, rather than death locations, because (for reasons given above) monitoring ceased before the deaths of some individuals.

\section{Results}

Causes of mortality recorded in the eight studies are summarized in Table 2. The data suggest that human causes are the most important contributor to adult wild dog mortality ( $46 \%$ of all deaths, and $62 \%$ of deaths due to known causes). However, such a preliminary examination of the data may not be sufficient to derive a realistic picture of threats to wild dogs.

\section{Reporting bias}

There was substantial variation in causes of death recorded among wild dogs subjected to different levels of monitoring. In particular, the level of human-caused mortality recorded among radio-collared adults and yearlings $(30 \% ; 33 / 109)$ was lower than that found in un-collared study animals $(52 \% ; 44 / 85)$ and non-study individuals of the same age class $\left(68 \% ; 38 / 53, \chi^{2}=22.3\right.$, $\mathrm{df}=2, \mathrm{P}<0.001)$. The recorded level of natural mortality shows the opposite pattern, with more natural deaths recorded among radio-collared individuals $(33 \%$ of 109 , compared with $19 \%$ of 85 un-collared study and $9 \%$ of 53 non-study animals of the same age class; $\chi^{2}=$ $12.5, \mathrm{df}=2, \mathrm{P}=0.002$ ). Similar variation was observed within specific mortality causes. For example, the proportion of road kills recorded among non-study animals (34\%) was markedly higher than that reported for collared (5\%) and un-collared (4\%) study animals, and the proportion of animals snared was far lower $(4 \%$, compared with $16 \%$ and $21 \%$ in collared and un-collared study animals respectively).

Reporting bias is the most likely explanation for this variation. For example, wild dogs killed on roads are conspicuous and hence likely to be reported even if they are not being systematically monitored. In contrast, individuals that are shot or snared may be concealed and not detected unless radio-collared. Because 
Table 2 Numbers of deaths of African wild dogs at eight study sites (Table 1) due to natural causes, disease, human causes and unknown causes.

\begin{tabular}{|c|c|c|c|c|c|c|c|c|c|}
\hline Cause & Kruger & $\begin{array}{l}\text { Hluhluwe- } \\
\text { iMfolozi }\end{array}$ & Venetia & Marakele & $\begin{array}{l}\text { Lower } \\
\text { Zambezi }\end{array}$ & Hwange & Savé & $\begin{array}{l}\text { Samburu- } \\
\text { Laikipia }\end{array}$ & Total (\%) \\
\hline \multicolumn{10}{|c|}{ Radio-collared adults and yearlings } \\
\hline \multicolumn{10}{|l|}{ Natural causes } \\
\hline $\begin{array}{l}\text { Natural injury or } \\
\text { accident }\end{array}$ & & & & & 1 & 3 & & & $4(4)$ \\
\hline Starvation & & & & & & & & & $0(0)$ \\
\hline Old age & & & & & & 3 & 1 & & $4(4)$ \\
\hline Other wild dogs & 5 & 1 & & & & 5 & & 1 & $12(11)$ \\
\hline Predator & 4 & 3 & 1 & & & 6 & & 2 & $16(15)$ \\
\hline Total natural causes & 9 & 4 & 1 & 0 & 1 & 17 & 1 & 3 & $36(33)$ \\
\hline Disease & 1 & & & & & & & 4 & $5(5)$ \\
\hline Total disease & 1 & 0 & 0 & 0 & 0 & 0 & 0 & 4 & $5(5)$ \\
\hline \multicolumn{10}{|l|}{ Human causes } \\
\hline $\begin{array}{c}\text { Road/train } \\
\text { accident }\end{array}$ & 1 & & & & & 4 & & & $5(5)$ \\
\hline Shot/speared & 4 & & & & & 4 & & 2 & $10(9)$ \\
\hline Poisoned & & 1 & & & & & & & $1(1)$ \\
\hline Snared & & & & & 1 & 15 & 1 & & $17(16)$ \\
\hline Total human causes & 5 & 1 & 0 & 0 & 1 & 23 & 1 & 2 & $33(30)$ \\
\hline Unknown causes & 26 & 1 & & & 1 & 6 & 1 & & $35(32)$ \\
\hline Total unknown & 26 & 1 & 0 & 0 & 1 & 6 & 1 & 0 & $35(32)$ \\
\hline Total radio-collared & 41 & 6 & 1 & 0 & 3 & 46 & 3 & 9 & 109 \\
\hline \multicolumn{10}{|c|}{ Individually identified (but not radio-collared) adults and yearlings } \\
\hline \multicolumn{10}{|l|}{ Natural causes } \\
\hline $\begin{array}{l}\text { Natural injury or } \\
\text { accident }\end{array}$ & 2 & 1 & 1 & & & 1 & & & $5(6)$ \\
\hline Starvation & & & & & & 1 & & & $1(1)$ \\
\hline Old age & & & & & & & & & $0(0)$ \\
\hline Other wild dogs & 3 & & 1 & & & & & & $4(5)$ \\
\hline Predator & 2 & & & & 3 & & 1 & & $6(7)$ \\
\hline Total natural causes & 7 & 1 & 2 & 0 & 3 & 2 & 1 & 0 & $16(19)$ \\
\hline Disease & & & & & 1 & & & & $1(1)$ \\
\hline Total disease & 0 & 0 & 0 & 0 & 1 & 0 & 0 & 0 & $1(1)$ \\
\hline \multicolumn{10}{|l|}{ Human causes } \\
\hline $\begin{array}{c}\text { Road/train } \\
\text { accident }\end{array}$ & & 1 & & & & 1 & 1 & & $3(4)$ \\
\hline Shot/speared & & & & 6 & & 5 & 5 & & $16(19)$ \\
\hline Poisoned & & & & & & & 7 & & $7(8)$ \\
\hline Snared & 4 & & & & & 5 & 9 & & $18(21)$ \\
\hline Total human causes & 4 & 1 & 0 & 6 & 0 & 11 & 22 & 0 & $44(52)$ \\
\hline Unknown causes & 23 & & & & & & 1 & & $24(28)$ \\
\hline Total unknown & 23 & 0 & 0 & 0 & 0 & 0 & 1 & 0 & $24(28)$ \\
\hline Total uncollared & 34 & 2 & 2 & 6 & 4 & 13 & 24 & 0 & 85 \\
\hline \multicolumn{10}{|c|}{ Adults and yearlings not individually identified } \\
\hline \multicolumn{10}{|l|}{ Natural causes } \\
\hline $\begin{array}{l}\text { Natural injury or } \\
\text { accident }\end{array}$ & & & & & & & 1 & & $1(2)$ \\
\hline Starvation & & & & & & & & & $0(0)$ \\
\hline Old age & & & & & & & & & $0(0)$ \\
\hline Other wild dogs & & & & & & & & & $0(0)$ \\
\hline Predator & 3 & & & & & & 1 & & $4(8)$ \\
\hline Total natural causes & 3 & 0 & 0 & 0 & 0 & 0 & 2 & 0 & $5(9)$ \\
\hline Disease & & & & & & & 2 & 3 & $5(9)$ \\
\hline Total disease & 0 & 0 & 0 & 0 & 0 & 0 & 2 & 3 & $5(9)$ \\
\hline \multicolumn{10}{|l|}{ Human causes } \\
\hline $\begin{array}{l}\text { Road/train } \\
\text { accident }\end{array}$ & 3 & & & & & & 7 & 8 & $18(34)$ \\
\hline Shot/speared & & & & & & & 1 & 2 & $3(6)$ \\
\hline Poisoned & & & & & & & 13 & & $13(25)$ \\
\hline Snared & 1 & & & & & & 1 & & $2(4)$ \\
\hline
\end{tabular}


Table 2 (continued)

\begin{tabular}{|c|c|c|c|c|c|c|c|c|c|}
\hline Cause & Kruger & $\begin{array}{l}\text { Hluhluwe- } \\
\text { iMfolozi }\end{array}$ & Venetia & Marakele & $\begin{array}{l}\text { Lower } \\
\text { Zambezi }\end{array}$ & Hwange & Savé & $\begin{array}{l}\text { Samburu- } \\
\text { Laikipia }\end{array}$ & Total (\%) \\
\hline Total human causes & 4 & 0 & 0 & 0 & 0 & 0 & 22 & 10 & $36(68)$ \\
\hline Unknown causes & & & & & & & 7 & & 7 (13) \\
\hline Total unknown & 0 & 0 & 0 & 0 & 0 & 0 & 7 & 0 & $7(13)$ \\
\hline Total non-study & 7 & 0 & 0 & 0 & 0 & 0 & 33 & 13 & 53 \\
\hline \multicolumn{10}{|l|}{ Pups } \\
\hline \multicolumn{10}{|l|}{ Natural causes } \\
\hline $\begin{array}{l}\text { Natural injury or } \\
\text { accident }\end{array}$ & 2 & & & & & & & & $2(2)$ \\
\hline Starvation & & & & & & & & & $0(0)$ \\
\hline Old age & & & & & & & & & $0(0)$ \\
\hline Other wild dogs & 17 & 1 & & & & 1 & 2 & & $21(19)$ \\
\hline Predator & 24 & & & & & 7 & 6 & & $37(33)$ \\
\hline Total natural causes & 43 & 1 & 0 & 0 & 0 & 8 & 8 & 0 & $60(53)$ \\
\hline Disease & 24 & 2 & & & & & 3 & & $29(26)$ \\
\hline Total disease & 24 & 2 & 0 & 0 & 0 & 0 & 3 & 0 & $29(26)$ \\
\hline \multicolumn{10}{|l|}{ Human causes } \\
\hline $\begin{array}{c}\text { Road/train } \\
\text { accident }\end{array}$ & & 1 & & & & 6 & 3 & & $10(9)$ \\
\hline Shot/speared & & & & & & 6 & 3 & 1 & $10(9)$ \\
\hline Poisoned & & & & & & & & & $0(0)$ \\
\hline Snared & 1 & & & & & 2 & & & $3(3)$ \\
\hline Total human causes & 1 & 1 & 0 & 0 & 0 & 14 & 6 & 1 & $23(20)$ \\
\hline Unknown causes & & & & & 1 & & & & $1(1)$ \\
\hline Total unknown & 0 & 0 & 0 & 0 & 1 & 0 & 0 & 0 & $1(1)$ \\
\hline Total pups & 68 & 4 & 0 & 0 & 1 & 22 & 17 & 1 & 113 \\
\hline
\end{tabular}

the carcasses of radio-collared wild dogs may be retrieved irrespective of the cause or location of the death, data from these animals probably provide the least biased estimate of mortality causes. We therefore restricted our subsequent analyses of mortality rates and causes to radio-collared animals. These more in depth analyses omitted pups, which cannot be safely radio-collared.

\section{Local variation in rates and causes of mortality of radio-collared animals}

Rates of mortality varied between study areas (Fig. 1), although small sample sizes mean that confidence limits are wide for most sites. The importance of particular mortality causes also varied locally (Table 2). Variation in the importance of snaring was particularly striking; this was the most important cause of mortality in some areas (e.g. Hwange) but never recorded in others (e.g. Samburu-Laikipia, Hluhluwe-iMfolozi). SamburuLaikipia was unusual in having a higher level of mortality recorded due to disease (four of nine deaths) compared with other areas combined (one of 100 deaths; $\chi^{2}=26.5$, df $\left.=1, \mathrm{P}<0.001\right)$. Kruger had the highest proportion of deaths from unknown causes (26 of 41 deaths, compared with 9 of 68 elsewhere; $\chi^{2}=27.3$, $\mathrm{df}=1, \mathrm{P}<0.001)$.

\section{Rates and causes of mortality inside and outside protected areas}

Among radio-collared wild dogs most that died inside protected areas died from natural causes, whereas most individuals that died outside died from human causes, irrespective of where they were originally collared (Fig. 2). Of 81 wild dogs radio-collared inside protected areas whose deaths were recorded, $16(20 \%)$ died outside reserve borders. Two (7\%) of 18 wild dogs collared outside Hwange National Park died inside, both from

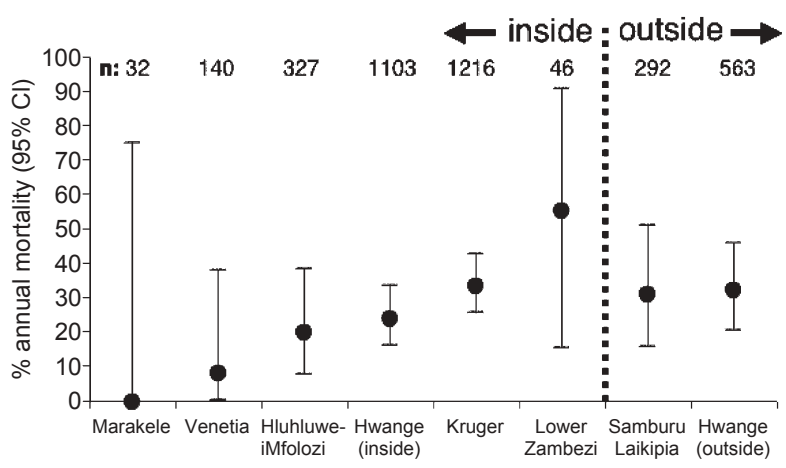

Fig. 1 Annual mortality rates (with exact binomial 95\% confidence intervals) of adult and yearling wild dogs radio collared inside and outside protected areas. Sample sizes give the numbers of wild dogmonths for which radio-collared animals were monitored at each site. Savé is omitted due to incomplete data on survivorship. 


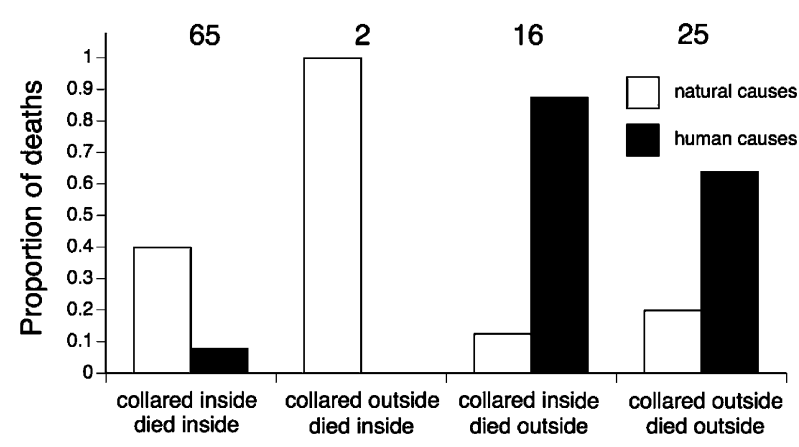

Fig. 2 Locations and causes of deaths of wild dogs radio-collared inside and outside protected areas. Proportions of natural and human caused mortalities do not add to one because some animals died from disease, or from unknown causes. Numbers above bars indicate sample sizes.

natural causes; all of the wild dogs studied in Kenya lived far from protected areas and the nine deaths of collared animals all occurred outside.

The data suggest that the annual adult mortality rate among wild dogs radio-collared inside reserves may be lower than that among dogs collared outside, although the differences were not statistically significant either when all data were combined (inside: 27.5\%, exact binomial 95\% confidence interval (CI) 22.4-33.1\%, outside: $32.0 \%$, CI $22.4-42.9 \%$; log rank test $\chi^{2}=2.64, \mathrm{df}=1, \mathrm{P}=$ 0.10 ) or considering only the study area where wild dogs were collared both inside and outside the same protected area (in and around Hwange National Park, Zimbabwe, inside: $24.1 \%$, CI $16.3-33.4 \%$, outside: $32.3 \%$, CI $20.6-$ $46.0 \%$; log rank test $\chi^{2}=2.21, \mathrm{df}=1, \mathrm{P}=0.14$ ).

While there was no significant difference in overall mortality rates inside and outside protected areas, rates of mortality due to different causes varied. Although the annual mortality rate due to natural causes was similar among wild dogs collared inside and outside reserves (inside: $10.3 \%$, CI $6.9-14.8 \%$, outside: $10.7 \%$, CI 4.8 $19.9 \%$; log rank test $\chi^{2}=0.08, \mathrm{df}=1, \mathrm{P}=0.78$ ), those collared outside experienced significantly higher mortality rates due to human causes (inside: $6.5 \%$, CI $3.8-10.3 \%$, outside: $20.3 \%$, CI $12.1-30.8 \%$; log rank test $\left.\chi^{2}=13.3, \mathrm{df}=1, \mathrm{P}<0.001\right)$.

\section{Causes of pup mortality}

Causes of pup mortality must be discussed with caution, because the difficulties of monitoring pups (which cannot safely be radio-collared, and may be concealed inside dens that cannot be disturbed without risking serious disruption) make it nearly impossible to obtain unbiased estimates. The data (Table 2) suggest that most pups die from natural causes (53\%) and disease (26\%). However, these average figures conceal local variation; for example 14 (64\%) of 22 pup deaths recorded outside Hwange National Park were human caused.

\section{Discussion}

\section{Mortality rates}

The rates of adult and yearling mortality presented here, calculated for radio-collared animals only, are roughly comparable with those estimated through intensive monitoring of collared and un-collared study animals, with disappearances distinguished from deaths based upon estimates of dispersal probability (Creel et al., 2004). Our data suggest that wild dogs living primarily outside reserves may experience higher mortality than those living mainly inside; while the difference we detected was not statistically significant, a larger sample size may confirm the trend in the future. Our analysis drew on data from only two projects that have radiocollared wild dogs outside reserves. As confidence intervals are wide (Fig. 1), it is not possible to draw firm conclusions about how mortality rates may vary between populations.

We made no attempt to measure rates of pup mortality because it was nearly impossible to adopt a measure that could be applied systematically across all study areas. While some studies are able to monitor the dens of habituated packs and measure litter sizes at first emergence, this is far more difficult where rocks or dense vegetation preclude vehicle access to dens, and in unprotected areas where study animals may be extremely wary.

\section{Causes of mortality}

In the broadest terms, the analyses presented here support the conclusions of the 1997 Action Plan (Woodroffe et al., 1997). The available data suggest that few wild dogs die of old age; most appear to be killed by people, predators or other wild dogs. Human-caused mortality (which may affect wild dogs collared inside, as well as outside, protected areas) includes snaring, road accidents, and deliberate shooting, spearing and clubbing. Although the relative importance of these mortality causes varies from place to place, no new external threats have been identified since 1997.

Woodroffe et al. (1997) emphasized the role that human-caused mortality may play in the dynamics of wild dog populations, even those nominally protected by reserves. However, our analyses suggest that anthropogenic mortality may be overestimated if datasets include animals that are not radio-collared (as was the case with Woodroffe et al.'s (1997) analyses). Even among radio-collared animals we recorded a high 
proportion of deaths to unknown causes because carcasses had decomposed or been scavenged before radio-collars were recovered. Because most such deaths occurred inside protected areas, and because few deaths of known cause inside protected areas were directly caused by people, it is likely that most deaths from unknown causes were natural. If this is the case then the data presented in Table 2 may overestimate the importance of anthropogenic relative to natural mortality.

Given these concerns about data quality, is anthropogenic mortality really a threat to wild dog populations? Anthropogenic mortality should only affect population viability if people (deliberately or accidentally) killed animals that would not otherwise have died of natural causes at a similar rate. Our analyses suggest that, outside protected areas at least, anthropogenic mortality probably does occur in addition to natural mortality: dogs collared outside reserves died from human causes at higher rates than those collared inside but they additionally died from natural causes at comparable rates. This suggests that anthropogenic mortality has the potential to undermine population viability outside reserves, and there are many examples of humans having eradicated wild dog populations living outside protected areas (Woodroffe et al., 1997). However, these data cannot be used to determine whether anthropogenic mortality is additive to natural mortality inside reserves. Although $20 \%$ of wild dogs radio-collared inside reserves died outside (almost entirely from human causes), this figure is highly specific to the reserves included in these analyses and will be influenced by their size, shape and fencing status; it cannot readily be extrapolated to other protected areas. Nevertheless, the sensitivity of model wild dog populations to sustained increases in adult mortality (Woodroffe et al., 1997; Mills et al., 1998), combined with evidence that anthropogenic mortality is additive outside reserves, suggests that human caused mortality has the potential to threaten populations living inside reserves, particularly those that are small relative to the scale of wild dog movements.

The possible importance of infectious disease as a threat to wild dog population persistence has also been discussed (Creel \& Creel, 2002; Laurenson et al., 2004). Our data do not highlight infectious disease as a major cause of adult mortality; among radio-collared animals only $5 \%$ of deaths were attributed to this cause, although disease may also explain some of the deaths due to unknown causes. Epidemics may be severe when they occur but they appear to occur rarely (in these study areas and during these monitoring periods at least). Hence, population viability analyses can most usefully represent disease threats to adults as episodic events. In contrast with the pattern described for adults and yearlings, $26 \%$ of pup deaths were attributed to disease (Table 2). Given the difficulties of accurately measuring causes of pup mortality, the reliability of this estimate is unknown. However if pup survival plays a key role in determining population viability (Cross \& Beissinger, 2001; Creel et al., 2004) disease may in some cases represent a chronic threat to some wild dog populations, as well as being an occasional acute threat.

Intraguild predation is a key aspect of wild dog ecology (Creel \& Creel, 1996; Mills \& Gorman, 1997). Among radio-collared wild dogs $15 \%$ of deaths were attributed to predation; some of the deaths due to unknown cause may also have been predation events. Although not the most important cause of mortality overall, predation did appear to be the most important form of natural mortality. Hence, wild dogs would be expected to have evolved behavioural responses to avoid predation, such as avoidance of larger predators and the areas they frequent (Creel \& Creel, 1996; Mills \& Gorman, 1997). For this reason, predation may still have a profound effect on wild dog ecology (through its effects on habitat choice and ranging behaviour) even if its demographic impacts cannot readily be assessed from our data. As wild dogs evolved alongside the predators that kill them, and yet remained widespread until recently, it may not be appropriate to consider predation a threat to wild dog populations unless recent changes such as habitat fragmentation exacerbate predation risks.

\section{Implications for monitoring}

Our data yield two clear results that have implications for the monitoring of mortality causes among wild dogs. Firstly, we detected consistent differences between monitoring methods in the proportions of deaths attributed to different causes. The simplest explanation for this pattern is that dogs that died from different causes varied in their detectability. Individuals that, for example, died conspicuously on a road would be likely to be reported whether or not they were being actively monitored, whereas individuals that were fatally injured by hyaenas and died in dense cover would rarely be detected unless specifically sought out with the assistance of radio telemetry. An alternative explanation is that radio-collaring might make wild dogs more susceptible to natural mortalities; handling (including radio-collaring) was hypothesized to have increased the rabies susceptibility of wild dogs in the Serengeti ecosystem by causing chronic stress (Burrows, 1992). However, available data (Woodroffe, 2001) tend not to support this hypothesis and variation in carcass detectability remains by far the most parsimonious explanation for the pattern we observed. 
Our assessment of the relative importance of various mortality factors has also been influenced by the high proportion of wild dogs that died from unknown causes. Most such deaths occurred at the Kruger study site and may reflect the frequency of monitoring there; most of the other studies aimed to locate collared animals twice per week (Hluhluwe-iMfolozi, Lower Zambezi, Samburu-Laikipia) or even daily (Venetia, Marakele), whereas the Kruger project only located collared animals once per month. This level of monitoring is adequate for measuring long-term population trends, which was the purpose of the study, but often precludes retrieval of carcasses soon enough to identify cause of death reliably.

These two findings suggest that accurate monitoring of mortality causes in wild dog populations is likely to require radio-collaring, using collars with mortality sensors, and monitoring those collars often enough to have a chance of retrieving carcasses before they decompose or are consumed by scavengers.

\section{Identification and mitigation of threats}

Our data provide a general picture of the mortality causes that affected the wild dog populations being studied but it is important to stress that threats vary substantially from site to site. For example, snaring is a serious problem at the Lower Zambezi site, but no snare-related deaths have been observed at SamburuLaikipia where local people rarely hunt wildlife with snares. This illustrates that the generalized data presented here may not apply to all populations, particularly in West and Central Africa where potentially important populations remain but have not been studied. Local management plans should, where possible, be based upon assessments of local threats.

The data presented here do not reveal any major new causes of wild dog mortality, suggesting that the tools currently being developed to address snaring, road kills, conflicts with game and livestock farmers, and disease, are appropriate for conservation management of the species (Woodroffe et al., 2005a). Fig. 2 suggests that most wild dogs that die inside protected areas die from natural causes; those that die from human causes die mainly outside protected areas, even if originally collared inside. As habitat fragmentation becomes more pronounced an increasing proportion of wild dog packs will be exposed to human activities and, hence, to anthropogenic mortality. Hence, while it is helpful to develop tools to mitigate human-caused mortality, conservation of this low-density wide-ranging species depends ultimately on maintaining and, where possible, expanding large wildlife areas. New findings suggest that, under some circumstances, wild dogs may be able to persist in areas devoted to game or livestock farming (Lindsey et al., 2005; Woodroffe et al., 2005b), potentially opening up much larger areas of Africa for wild dog conservation. More information on the possibilities for wild dog persistence outside reserves is clearly a priority because unprotected lands are likely to be important for the long-term conservation of ecologically functional wild dog populations.

\section{Acknowledgements}

These data were collated in the course of a workshop supported by the Wildlife Conservation Society, USA, and hosted by SANParks, South Africa. We also thank the many supporters and collaborators who contributed to the collection of the data discussed in this article.

\section{References}

Burrows, R. (1992) Rabies in wild dogs. Nature, 359, 277.

Caughley, G. (1994) Directions in conservation biology. Journal of Animal Ecology, 63, 215-244.

Creel, S. \& Creel, N.M. (1998) Six ecological factors that may limit African wild dogs, Lycaon pictus. Animal Conservation, 1, $1-9$

Creel, S. \& Creel, N.M. (2002) The African Wild Dog: Behavior, Ecology and Conservation. Princeton University Press, Princeton, USA

Creel, S., Mills, M.G.L. \& McNutt, J.W. (2004) Demography and population dynamics of African wild dogs in three critical populations. In The Biology and Conservation of Wild Canids (eds D.W. Macdonald \& C. Sillero-Zubiri), pp. 337-350. Oxford University Press, Oxford, UK.

Creel, S.R. \& Creel, N.M. (1996) Limitation of African wild dogs by competition with larger carnivores. Conservation Biology, 10, 1-15.

Cross, P.C. \& Beissinger, S.R. (2001) Using logistic regression to analyse the sensitivity of PVA models: a comparison of methods based on African wild dog models. Conservation Biology, 15, 1335-1346.

Heisey, D.M. \& Fuller, T.K. (1985) Evaluation of survival and cause-specific mortality rates using telemetry data. Journal of Wildlife Management, 49, 668-674.

IUCN (2006) 2006 IUCN Red List of Threatened Species. IUCN, Gland, Switzerland [http://www.iucnredlist.org, accessed 24 January 2007].

Laurenson, M.K., Cleaveland, S., Artois, M. \& Woodroffe, R. (2004) Canids and disease. In Wild Canids: Status Survey and Conservation Action Plan (eds C. Sillero-Zubiri \& D.W. Macdonald), pp. 246-256. IUCN, Gland, Switzerland.

Lindsey, P.A., Du Toit, J.T. \& Mills, M.G.L. (2005) The distribution and population status of African wild dogs Lycaon pictus outside protected areas in South Africa. South African Journal of Wildlife Research, 34, 143-151.

Maddock, A.H. \& Mills, M.G.L. (1994) Population characteristics of the African wild dogs Lycaon pictus in the eastern Transvaal lowveld, South Africa, as revealed through photographic records. Biological Conservation, 67, $57-62$.

Mills, M.G.L., Ellis, S., Woodroffe, R., Maddock, A., Stander, P., Rasmussen, G., Pole, A., Fletcher, P., Bruford, M., Wildt, D., 
Macdonald, D.W. \& Seal, U.S. (1998) Population and Habitat Viability Assessment for the African Wild Dog (Lycaon pictus) in Southern Africa. IUCN/SSC Conservation Breeding Specialist Group, Apple Valley, USA.

Mills, M.G.L. \& Gorman, M.L. (1997) Factors affecting the density and distribution of wild dogs in the Kruger National Park. Conservation Biology, 11, 1397-1406.

Pollock, K., Winterstein, S.R., Bunck, C.M. \& Curtis, P.D. (1989) Survival analysis in telemetry studies: the staggered entry design. Journal of Wildlife Management, 53, 7-15.

Woodroffe, R. (2001) Assessing the risks of intervention: immobilization, radio-collaring and vaccination of African wild dogs. Oryx, 35, 234-244.

Woodroffe, R. (2003) Conserving a cooperative species. Trends in Ecology and Evolution, 18, 109-110.

Woodroffe, R., André, J.-M., Andulege, B., Bercovitch, F., Carlson, A., Coppolillo, P.B., Davies-Mostert, H., Dickman, A.J., Fletcher, P., Ginsberg, J.R., Hofmeyr, M., Laurenson, M.K., Leigh, K., Lindsey, P.A., Lines, R., Mazet, J.K., McCreery, K., McNutt, J.W., Mills, M.G.L., Msuha, M., Munson, L., Parker, M.N., Pole, A., Rasmussen, G.S.A., Robbins, R., Sillero-Zubiri, C., Swarner, M.J. \& Szykman, M. (2005a) Tools for Conservation of the African Wild Dog: Do We Know Enough? What More Do We Need to Know? Wildlife
Conservation Society/IUCN Species Survival Commission Canid Specialist Group, New York, USA, and Oxford, UK. Woodroffe, R., Ginsberg, J.R. \& Macdonald, D.W. (1997) The African Wild Dog: Status Survey and Conservation Action Plan. IUCN, Gland, Switzerland.

Woodroffe, R., Lindsey, P.A., Romañach, S.S., Stein, A. \& ole Ranah, S.M.K. (2005b) Livestock predation by endangered African wild dogs (Lycaon pictus) in northern Kenya. Biological Conservation, 124, 225-234.

Woodroffe, R., McNutt, J.W. \& Mills, M.G.L. (2004) African wild dog. In Foxes, Wolves, Jackals and Dogs: Status Survey and Conservation Action Plan, 2nd edition (eds C. SilleroZubiri \& D.W. Macdonald), pp. 174-183. IUCN, Gland, Switzerland.

\section{Biographical sketches}

The authors are all members of the African Wild Dog Working Group, part of the IUCN/Species Survival Commission Canid Specialist Group. They are past and present leaders of field projects dedicated to the biology and conservation of African wild dogs. 